\title{
MEMBERS OF THE COUNCIL
}

\section{2 \\ OfFICERS}

H. B. Fine, President.

$\left.\begin{array}{l}\text { H. F. BLIChFeLdt, } \\ \text { Henry Taber, }\end{array}\right\}$ Vice-Presidents.

F. N. CoLE, Secretary.

J. H. TANNER, Treasurer.

D. E. SMIтH, Librarian.

F. N. CoLe,

E. W. Brown, $\}$ Committee of Publication. VIRGIL SNYDER,

\section{Ex-Presidents}

J. H. VAN AMringe, Emory McClintock, G. W. HrLL,
R. S. WOODWARD, ELIAKIM H. MOORE, T. S. Fiske,
W. F. OsGood, H. S. WhITE, Maxime Bôcher.

\section{Elected Members}

To Serve until December, 1912
D. R. Curtiss,
L. P. EISENhart,
J. C. Fields,
P. F. Sмiтh.

To Serve until December, 1913
H. F. BLICHFELDT,
C. J. KEYSER,
J. L. Coolidge,
J. W. Young.

To Serve until December, 1914
A. В. СовLе,
Oswald Veblen,
E. W. Davis,
E. B. Wilson.

Editorial Committee of the Transactions

Maxime BôCher,

H. S. White,

L. E. Diokson 